\title{
The Stoppani Collection of Large Bivalves (Bivalvia, Megalodontida) from the Upper Triassic of Lombardy, Italy
}

\author{
Giorgio Teruzzi
}

\begin{abstract}
During a reorganisation of the MSNM's palaeontological collections, we uncovered specimens from the original collection of Antonio Stoppani. These included around one hundred original fragments of megalodontid bivalves (mostly internal moulds) from the Upper Triassic of Lombardy, and 14 plaster casts of original fossils, and hypothetical internal mould and valve reconstructions. Among this materials an original fragment and 8 moulds were illustrated in Stoppani, 1860-65 in his appendix on large bivalves from the Upper Triassic of Lombardy. One of the moulds is of the holotype of Conchodon infraliasicus Stoppani, 1860-65.
\end{abstract}

Key words: Bivalvia, Megalodontide, Upper Triassic, Stoppani.

Riassunto - Nel corso del riordino delle Collezione di Paleontologia del MSNM sono stati riconosciuti come appartenenti alla originale collezione di Antonio Stoppani un centinaio di frammenti originale di modelli interni di bivalvi megalodonti del Triassico superiore lombardo e 14 modelli in gesso, alcuni corrispondenti a calchi di esemplari originali, altri a ricostruzioni di modelli interni o a ricostruzioni ipotetiche di valve. Un esemplare originale e 8 modelli sono stati figurati da Stoppani, $1860-65$ nella sua memoria sui grandi bivalvi del Triassico superiore lombardo. Uno di questi modelli è il calco dell'olotipo di Conchodon infraliasicus Stoppani.

Parole chiave: Bivalvia, Megalodontide, Triassico superiore, Stoppani.

Between 1860 and 1865, Antonio Stoppani published an extensive scientific paper on megalodontid bivalves of the Upper Triassic of Lombardy. He based this study on specimens from the Lombardian Prealps, which he had collected himself or that had been given to him by his geologist colleagues either as original specimens or as casts. This paper formed part of Volume II of Paléontologie Lombarde, entitled Géologie et Paléontologie des Couches à Avicula Contorta en Lombardie; the study on large bivalves was contained in Appendix 2, Sur les

\footnotetext{
Sezione di Paleontologia degli Invertebrati, Museo di Storia Naturale, Corso Venezia 55, 20121 Milano, Italia.

E-mail: giorgio.teruzzi@comune.milano.it

(C) 2015 Giorgio Teruzzi
}

Received: 24 ${ }^{\text {th }}$ March 2015

Accepted for publication: $12^{\text {nd }}$ May 2015
Grandes Bivalves Cardiformes aux Limites Supérieures et Inférieures des Couches à A. contorta. The study of the original material was often difficult as fossils are usually represented by internal moulds strongly cemented with the matrix and hard to isolate as complete specimens. Stoppani solved this problem by reconstructing the original shape of the shell from different fragmentary specimens of the internal moulds or of the shells, using also plaster casts of the negative impressions of hinges preserved on the internal moulds, and hypothetical plaster reconstructions of the valves. Moulds and reconstructions were made by Angelo Maestri, a naturalist-physician from Pavia who was conservator and curator of the museum of the University of Pavia and well-known for his waxworks of anatomy, pathology and physiology of invertebrates as well as vertebrates and mushrooms (Stoppani, 1860-65: 243, 244; Rovati et al., 2007). Some of these reconstructions served as a model for the artist who illustrated the paper by Stoppani.

Parts of the Museo di Storia Naturale di Milano's collection were destroyed or lost after the 1943 bombing that severely damaged the museum. For decades, the specimens used by Stoppani for his scientific works were considered lost. Following the museum's post-war reconstruction, the unpublished specimens of the Stoppani collection that had been partly recovered were ordered systematically and integrated into the museum's general collection of fossil invertebrates. Among these, Fantini Sestini \& Motta, 1983, identified some coral specimens described in Stoppani, 1860-65. Later, Garassino, 1994, published a catalogue of the collection used by Stoppani for his important paper on Ladinian fossils from the Grigne massif, entitled Les Pétrifications d'Esino (Stoppani, 1858-60). These specimens were found by Prof. Silvio Renesto - at the time curator of the Museum of the Institute of Geology and Palaeontology, University of Milan - in a basement of the institute, where they probably had been stored prior to World War II. This collection is currently housed at the Museo di Storia Naturale di Milano.

Among the specimens recovered after the bombing and that had not been catalogued because they lacked an inventory number or identification tag, were around one hundred fragments of Upper Triassic megalodontid bivalves, partly blackened by the fire that broke out in 1943. They were found in drawers labelled simply "Col- 
lezione Stoppani". Among this material was a fragment of Dicerocardium jani illustrated in Stoppani, 1860-65, T. 46, Fig. 3. Thirteen other fragments were identified as fitting together, accounting for a total of 6 single, incomplete specimens, none of which was illustrated by Stoppani. The condition of the specimens suggests that the original material used by Stoppani for the appendix on large bivalves only partially survived the bombing: this was borne out by the facts that all the specimens illustrated by Stoppani except one were missing, and that fresh fractures, probably caused by the blasts, could be easily identified on the surface of the specimens and distinguished from old, more or less altered fractures. Because the fresh fractures on these fragments could be matched up only in a few cases, it was concluded that the lacking fragments had not been recovered and were lost.

Fourteen plaster casts were found together with the original fossil fragments. These were both casts of original fossils and, above all, hypothetical reconstructions of internal moulds or of the original valves of some taxa. Some of these plaster casts were illustrated in the Stoppani paper.

Below is a list of the recovered specimens that we could identify. They are listed following Stoppani's 186065 original classification; their current taxonomy is beyond the scope of this article.

\section{ORIGINAL SPECIMENS ILLUSTRATED BY STOPPANI}

Dicerocardium jani Stoppani, 1860-65

MSNM i28031 - Fig. 1

Dicerocardium jani Stoppani, 1860-1865, Tab. 46, fig. 3.

Part of the hinge of a left valve. This is the only surviving original specimen of those illustrated by Stoppani.

\section{PLASTER CASTS AND RECONSTRUCTIONS ILLUSTRATED OR NOT BY STOPPANI}

\author{
Conchodon infraliasicus Stoppani, 1860-65
}

MSNM i28032 - Fig. 2

Conchodon infraliasicus Stoppani 1860-1865, Tab. 38, figs. 3-5.

Plaster cast of an internal mould, painted in dark grey. The fossil was probably collected by Balsamo-Crivelli at the then Villa Frizzoni (now Villa Crella) in San Giovanni di Bellagio (CO) (Stoppani, p. 244). The original specimen, specifically designated as the type for Conchodon infraliasicus (Stoppani, p. 248) by the author, is considered lost.

MSNM i28033 - Fig. 3

Conchodon infraliasicus Stoppani 1860-1865, Tav. 39, fig. 1.
Plaster reconstruction of a right valve. The size and ornamentation (fine concentric striae on the outer surface of the shell) match those of the specimen illustrated in T. 39, fig. 1 (Stoppani, p. 244). However, the hinges are dissimilar: in the illustration, the large front hinge tooth is globose and more irregular than that of the reconstruction, and there are two parallel cardinal teeth instead of one. Stoppani (p. 244) stated that the two cardinal teeth were a bit more prominent in the drawing, but the second tooth is not even roughly delineated in the valve reconstruction. The hinge seems to correspond more to the negative relief embossed in the plaster cast of the internal mould. A number ' 2 .' is engraved at the centre of the interior surface of the valve: what this refers to is unknown.

These differences raised doubts on whether the hinge illustrated in T. 39, fig. 1 corresponds to this plaster reconstruction. However, comparing it with the original plaster cast of the internal mould (MSNM i28032), from which the reconstruction was derived, we noticed that the grooves (in positive relief) inside the reconstructed valve perfectly matched those on the right side of the cast of the mould: these grooves (attributed by Stoppani, p. 244, to 'de petits dégats causés comme par des vers lithophages', but that most likely represent the negative imprint of tube worms encrusting the interior of the original valve) are not present on the inner face of the valve in T. 39, fig. 1, nor on the illustration of the original internal mould given in T. 38, fig. 5. Moreover, the hinge of the original mould perfectly matches that of the reconstruction. It must be assumed, therefore, that the hinges illustrated in T. 39 were 'adapted' by the author to show what he thought was their original appearance. In particular, the large cardinal tooth is not globose as in the reconstruction, and only one cardinal tooth is apparent. In the plaster cast of the mould, the left valve has an impression left by a possible second, not very evident, tooth (Stoppani emphasized that the two teeth in the drawing were 'exaggerated') and a spherical cavity that corresponds perfectly to the globose cardinal tooth. Clearly, the decisions made by Stoppani when recreating the hinge were driven by the characteristics of the traces present in the mould of the left valve. Both valves were drawn as mirror images of each other, whereas Maestri's reconstruction matched the original conformation.

\section{Dicerocardium jani Stoppani, 1860-65}

MSNM i 28034 a,b,c - Fig. 4

Dicerocardium jani Stoppani, 1860-65, T. 41-42.

Reconstruction of a right valve ( 2 copies, MSNM i 28034 a,c); reconstruction of a left valve, MSNM i28034 b. Stoppani stated (p. 244) that he figured at Tab. 41, 42 and 43 the only specimen with intact umbos, integrating the missing part of the shell with that of other specimens. He did not mention creating reconstructions of both valves, as he had done for $C$. infraliasicus. In the reconstruction, the right and the left valve fit perfectly together: the two halves are remarkably similar to the illustration of $D$. jani (T. 41-42), and are also the same size. When viewed at the correct angle, the right valve is exactly the same 
as that drawn in T. 43. Internal views of two separated valves of $D$. jani are given in Stoppani, 1873, p. 364, fig. 67; the illustration is not as accurate as that of the plates in Paléontologie Lombarde and may have been executed directly from the reconstructions in question.

\section{Dicerocardium curionii Stoppani, 1860-1865}

MSNM i28035 - Fig. 5

Dicerocardium curionii Stoppani, 1860-65, T. 51, figs. 1-3.

Slightly damaged plaster cast of an internal mould of a specimen originally in the Stoppani collection and lost in 1943.

MSNM i28036 a,b - Fig. 6

Dicerocardium curionii Stoppani, 1860-65. T. 52.

Reconstructions of the left and right valves of the original shell. The interior surface was based on the plaster cast of a specimen in the Stoppani collection illustrated in T. 51, figs. 1-3, of which the previously cited cast has survived. The exterior of the shell was based on the original illustrated in T. 51, figs. 4 and 5, of the Curioni Collection, and is considered lost.

\section{Dicerocardium ragazzonii Stoppani, 1860-65}

Four plaster reconstructions of complete internal moulds, and a reconstruction of the right valve. It is believed that the moulds are hypothetical reconstructions based on fragmented specimens. In fact, Stoppani underlined the incompleteness of the specimen at his disposal, and only fragments of internal moulds are illustrate. None of the plaster moulds corresponds with the figures in Tabs. 53-55.

\section{MSNM i28042 - Fig. 7}

Plaster reconstruction of an internal mould with elongated umbonal region.

MSNM i28039 - Fig. 8

Plaster reconstruction of an internal mould complete with both valves; it is a probably a hypothetical reconstruction of the form with extremely elongated, horn-shaped umbones of which fragmentary moulds are figured at. T. 55, figs. 1-5, with stippled lines indicating the missing parts. This reconstruction was not illustrated by Stoppani.

\section{MSNM i28038 - Fig. 9}

Hypothetical plaster reconstruction of an original right valve. It fits well with the previously described internal mould (MSNM i28039). It was not illustrated by Stoppani, and differs from the reconstruction given by Stoppani in T. 54, fig. 4 of a left valve, because it does not depict the external striped ornamentation.

MSNM i28030, MSNM i28041 - Fig. 10

To copies of the same hypothetical plaster reconstruction of an internal mould. This reconstruction differs from MSNM i28042 and 28039, in that the umbonal area is shorter and broader; however, the hinge is similar.

Megalodon guembelii Stoppani, 1860-65

MSNM i28042 - Fig. 11

Megalodon guembelii Stoppani 1860-65, T. 56, figs. 1-3

Cast of an internal mould: it corresponds to the original specimen from Songavazzo (Bergamo), figured by Stoppani, T. 56, figs. 1-3.

\section{Acknowledgments}

Thanks are due to Dr.Monica Leonardi for critical reading of the manuscript.

\section{REFERENCES}

Garassino A., 1992 - Catalogo dei tipi del Museo Civico di Storia Naturale di Milano. I molluschi Fossili del Calcare di Esino della Collezione Stoppani. Atti Soc. Ital. Sci. Nat. e Museo Civ. Milano, 133: 245-260.

Fantini Sestini N. \& Motta E., 1983 - I Coralli del Calcare di Zu. Riv. It. Paleont. Strat., 89 (1): 3-30.

Stoppani A., 1858-60 - Les Pétrifications d'Esino. Paléontologie Lombarde, I.

Stoppani A., 1860-65 - Géologie et Paléontologie des Couches à Avicula Contorta en Lombardie. Paléontologie Lombarde, III.

Stoppani A., 1873 - Corso di Geologia. Vol. II. 

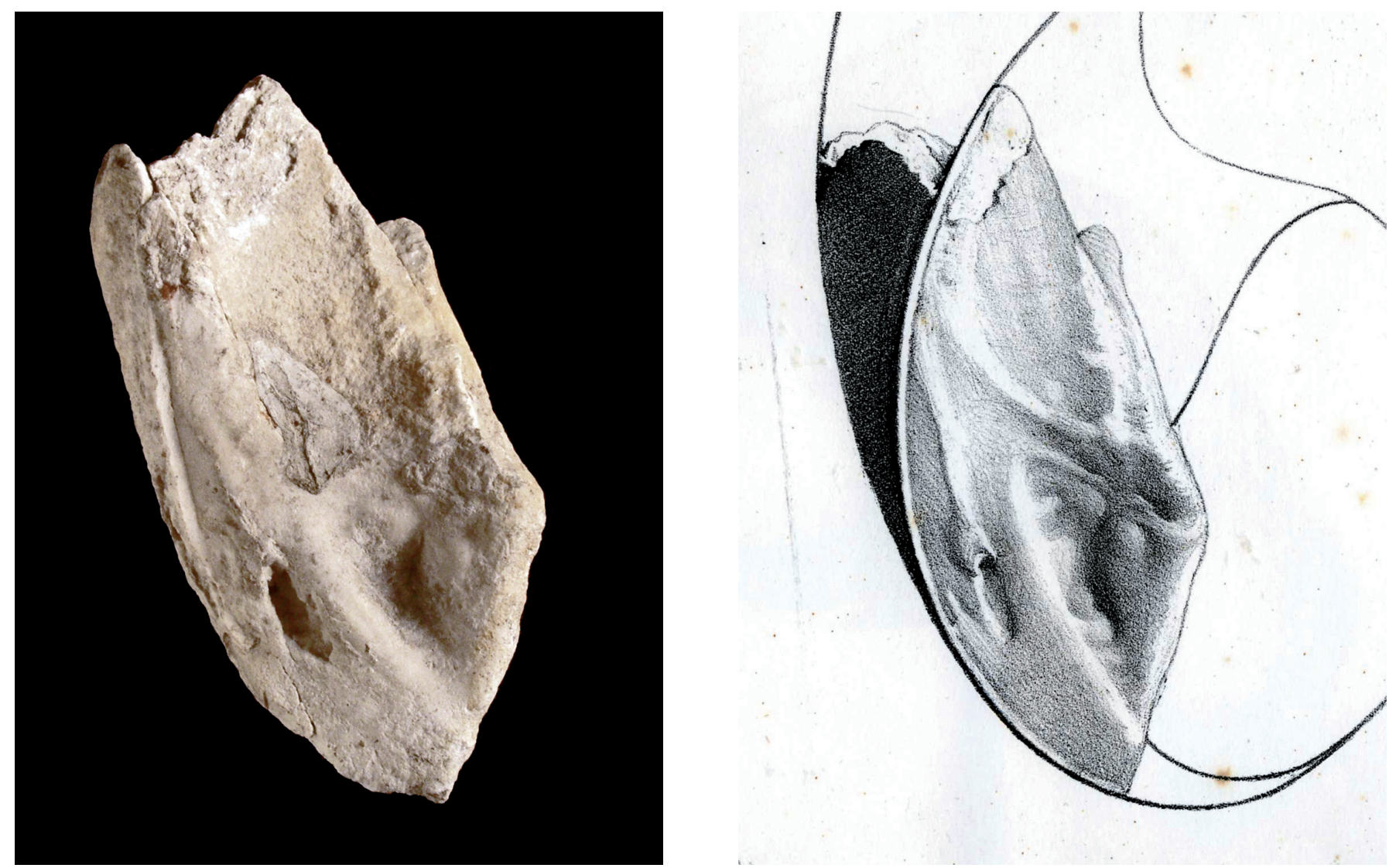

Fig.1 - MSNM i28031. Original fragment of left valve of Dicerocardium jani Stoppani, 1860-65. Stoppani 1860-65, Tav. 46, fig. 3. x $1 \mathrm{ca}$.
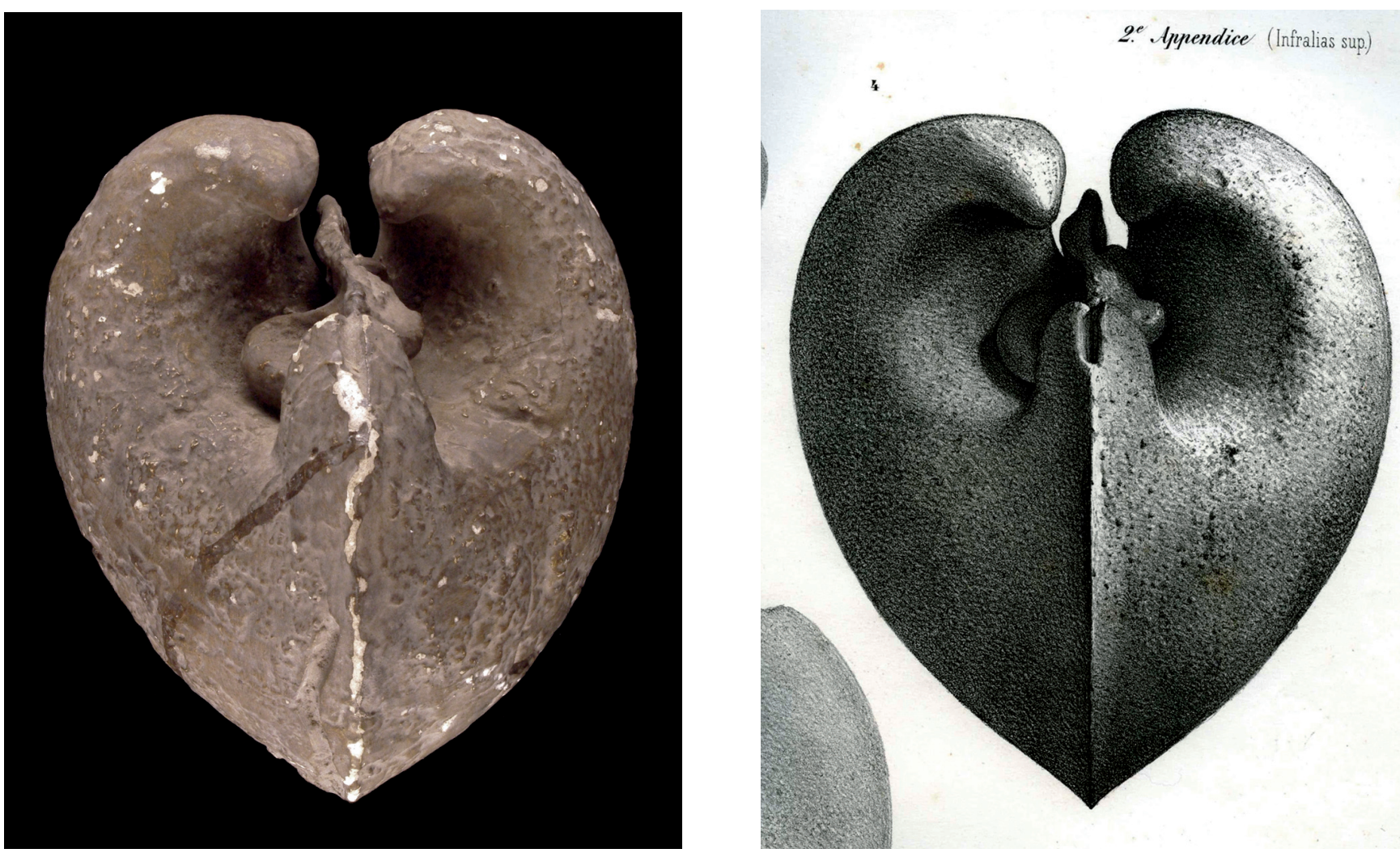

Fig.2 - MSNM i28032. Conchodon infraliasicus Stoppani, 1860-65. Plaster cast of the type; the original specimen is lost. Stoppani, 1860-65, Tav. 38, figg. 3-5. x 0.54 ca. 

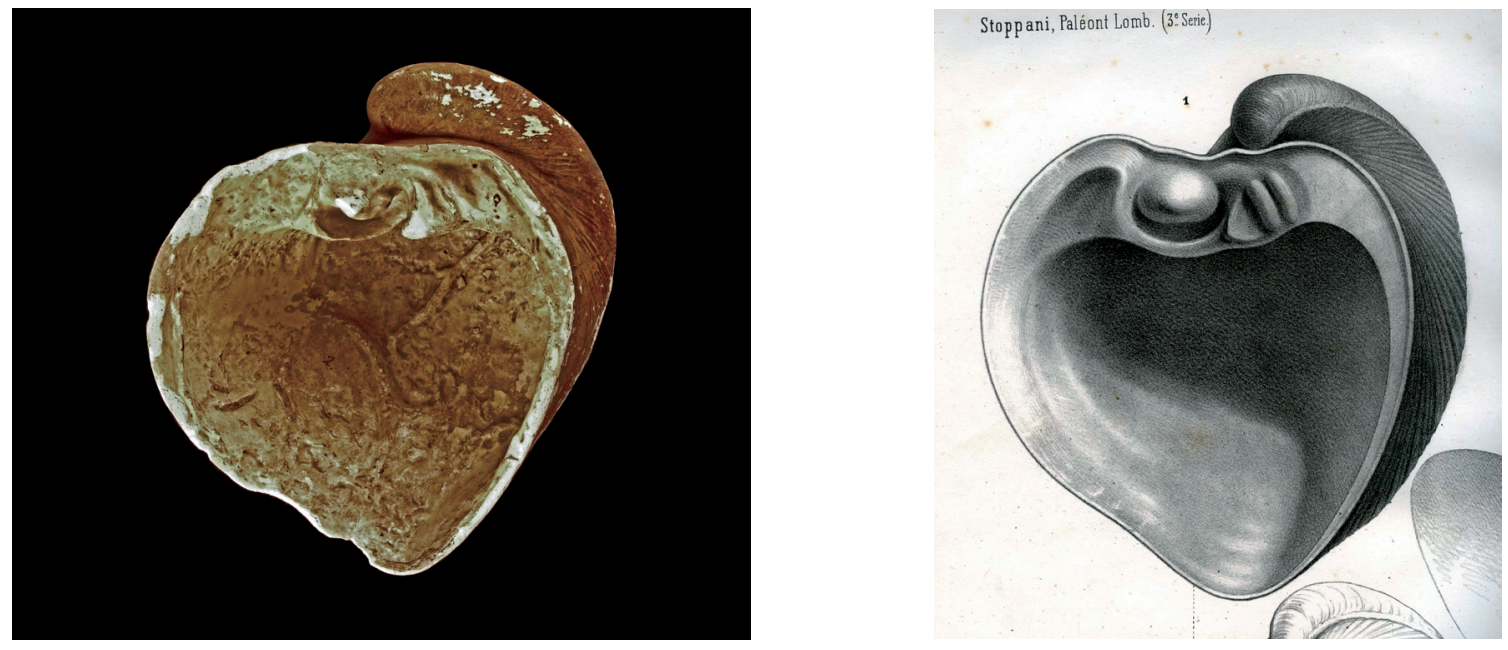

Fig.3 - MSNM i28033. Conchodon infraliasicus Stoppani, 1860-65. Hypothetical plaster reconstruction of a right valve. A) external view. B) internal view. Stoppani, 1860-65, Tav. 39, fig. 1. x 0.26 ca.
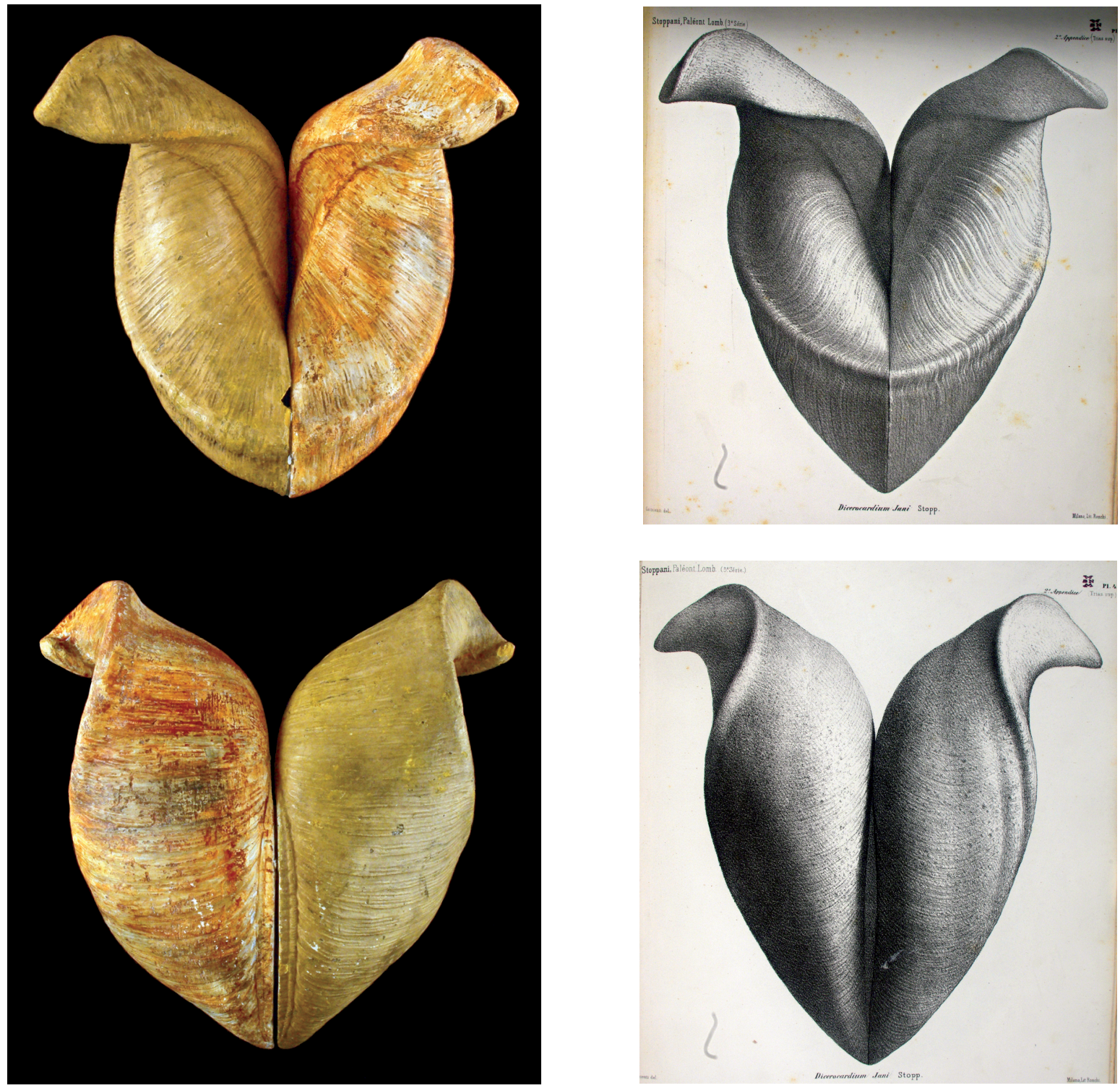

Fig.4 - MSNM i28034 a,b. Plaster reconstruction of the shell of Dicerocardium jani Stoppani 1860-65, as in Stoppani, 1860-65, Tavv. 41-42. A) anterior view. B) posterior view. x $0.28 \mathrm{ca}$. 

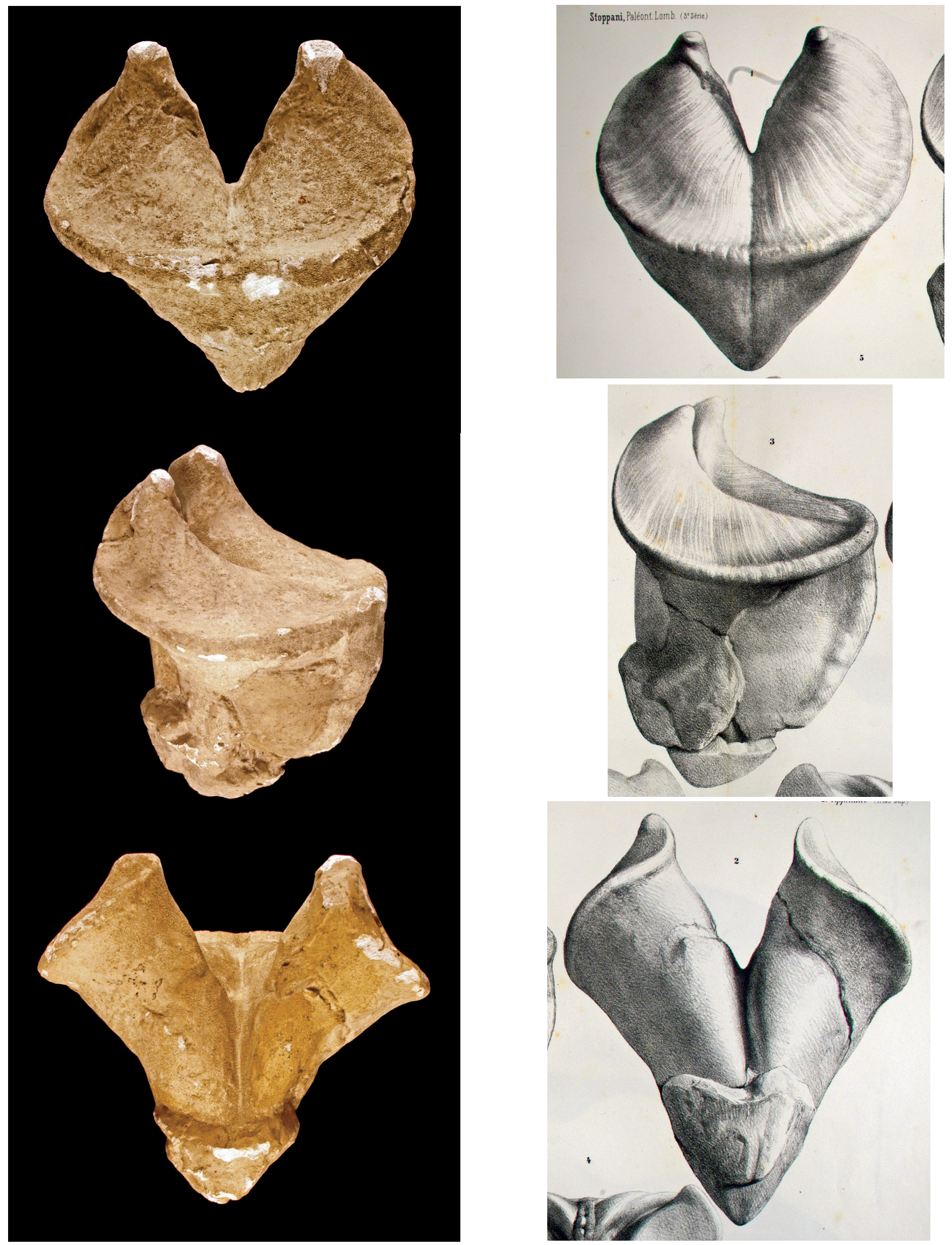

Fig.5 - MSNM i28035. Dicerocardium curionii Stoppani 1860-65; plaster cast of a specimen from Stoppani collection. A) anterior view. B) lateral view. C) posterior view. Stoppani, 1860-65, Tav. 51, fig. 1-3. x 0.43 ca. 

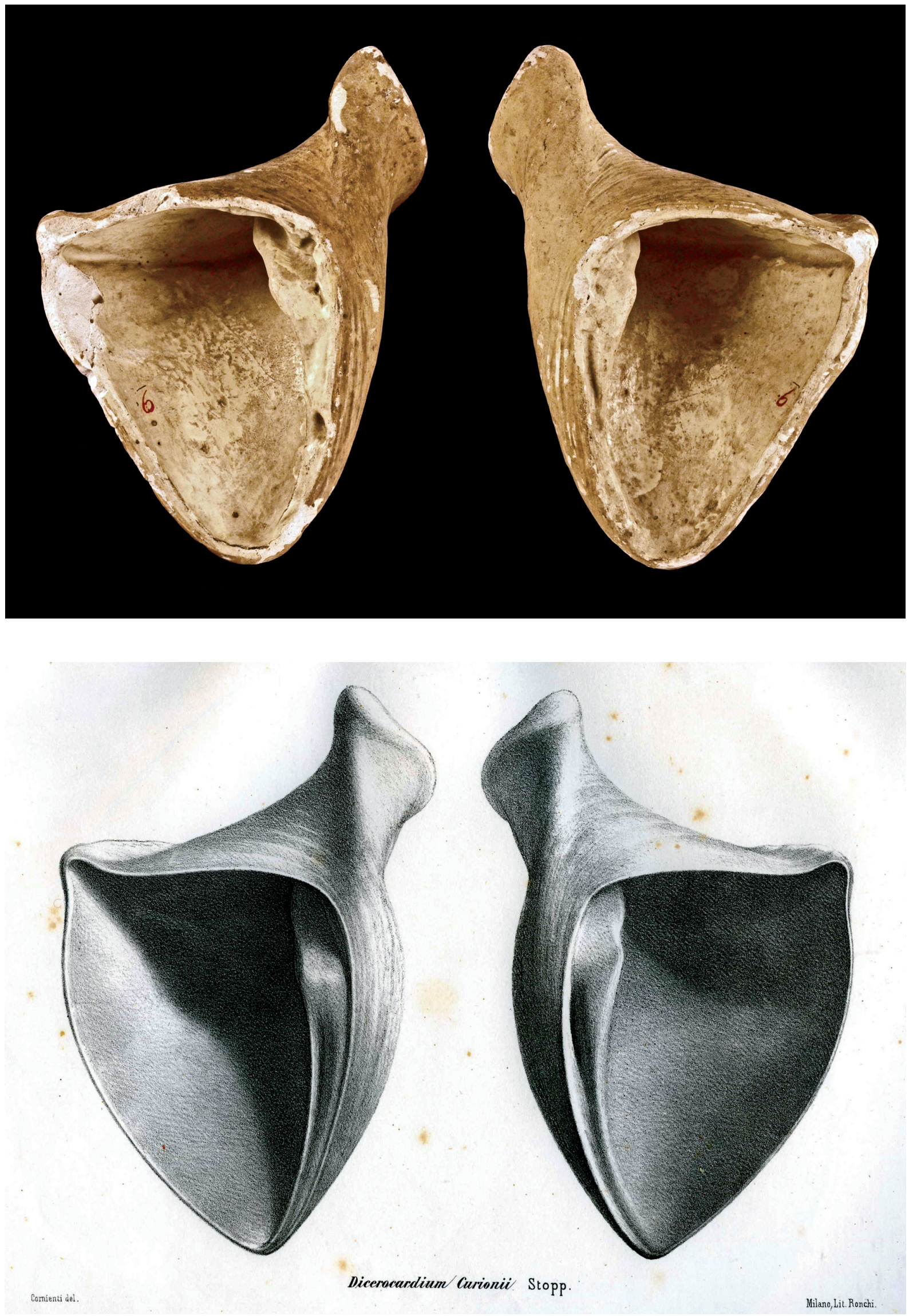

Fig.6 - MSNM i28036 a,b. Dicerocardium curionii Stoppani, 1860-65. Reconstruction of A) right valve and B) left valve. Stoppani, 1860-65. Tav. 52. x 0.5 ca. 


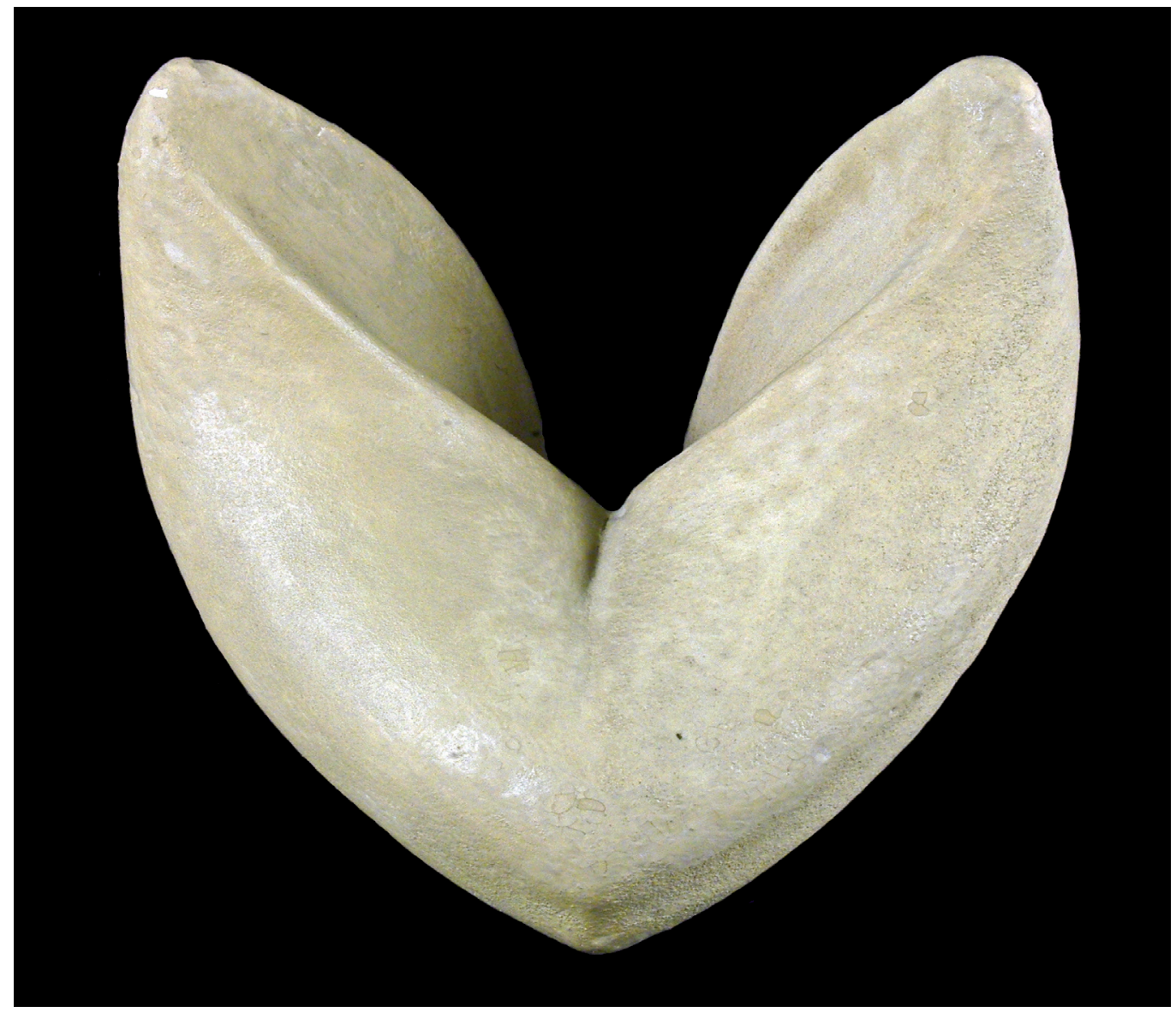

Fig.7 - MSNM i28042. Dicerocardium ragazzonii Stoppani, 1860-65. Plaster reconstruction of an internal mould. x 0.74 ca.

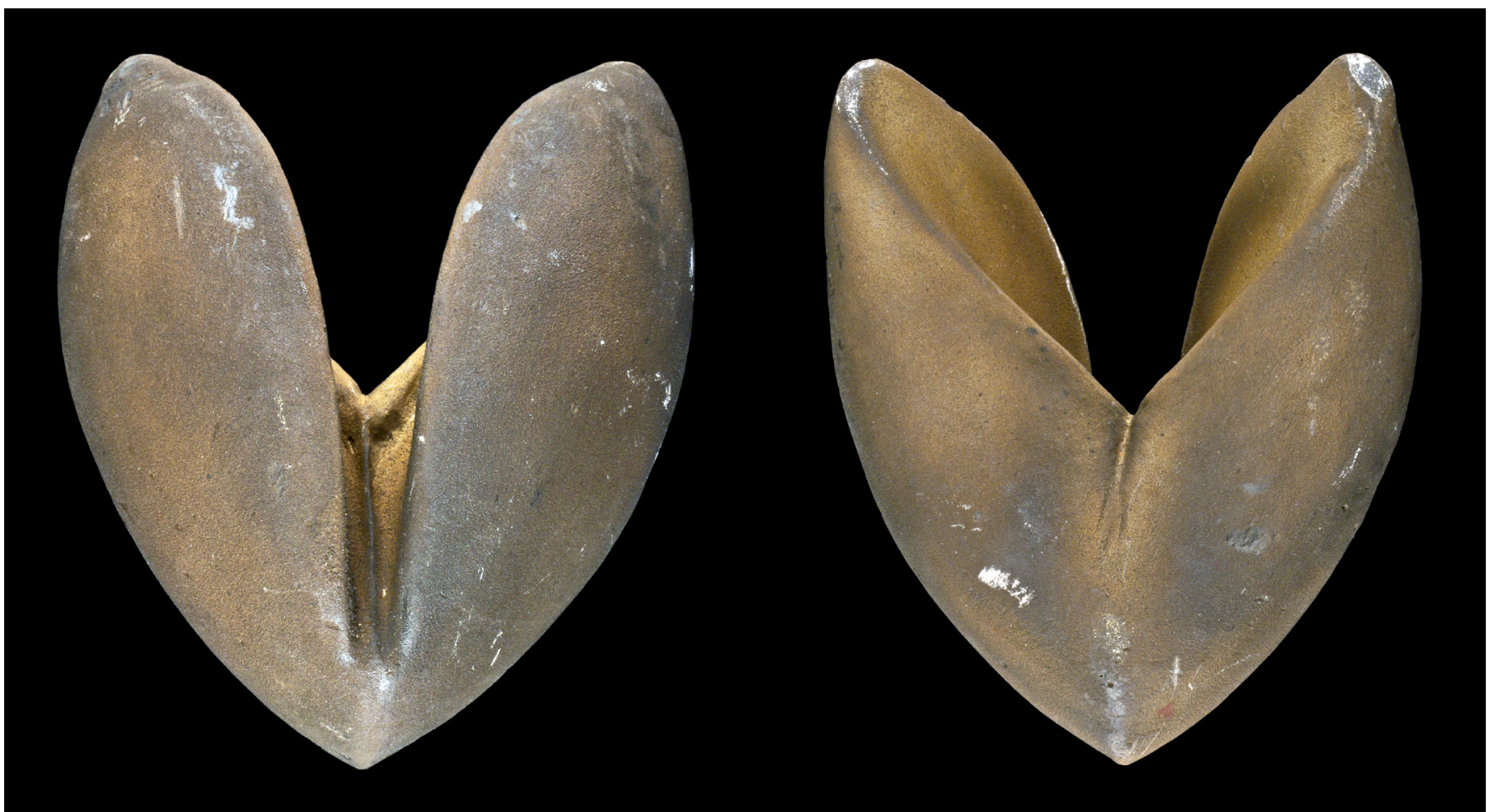

Fig.8 - MSNM i28039. Dicerocardium ragazzonii Stoppani 1860-65. Plaster reconstruction of an internal mould, similar to the form illustrated by Stoppani at Tav. 55. A) anterior view. B) posterior view. x $0.57 \mathrm{ca}$. 


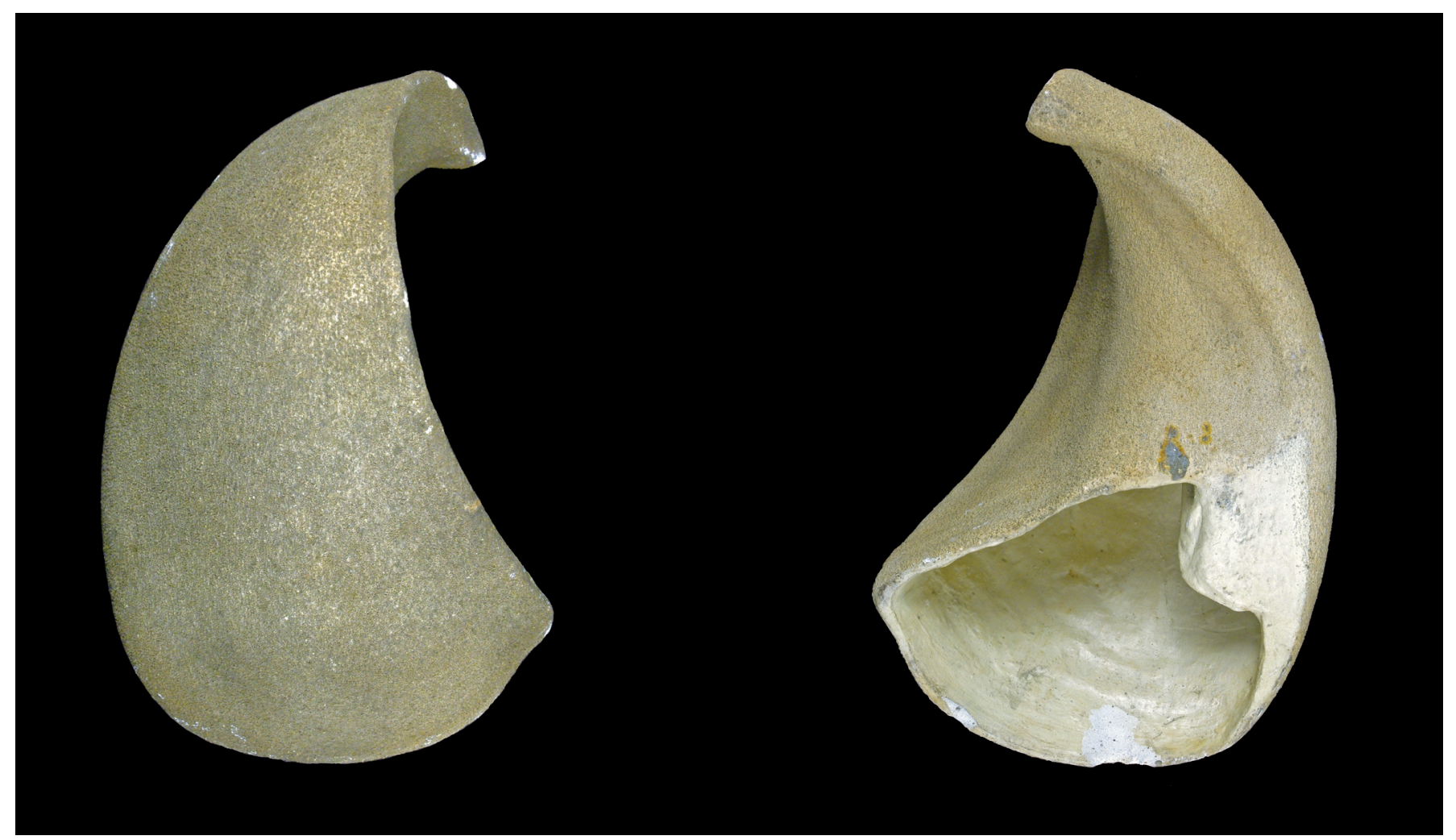

Fig.9 - MSNM i28038. Dicerocardium ragazzonii Stoppani 1860-1865. Plaster reconstruction of a right valve, not illustrated by Stoppani. x 0.42 ca.

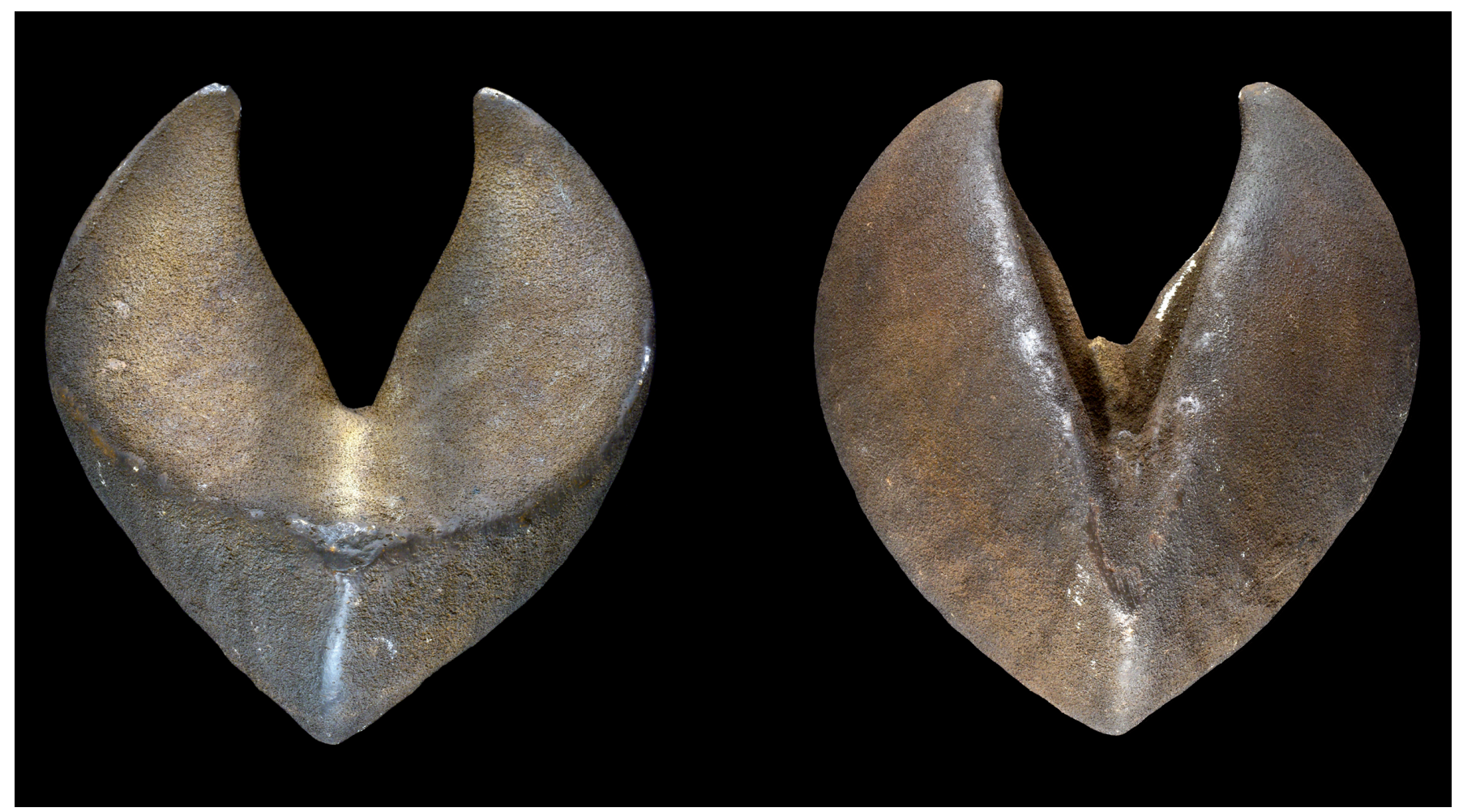

Fig.10 - MSNM i28040. Dicerocardium ragazzonii Stoppani, 1860-65. Plaster reconstruction of an internal mould. A) anterior view. B) posterior view. $x 0.48 \mathrm{ca}$. 

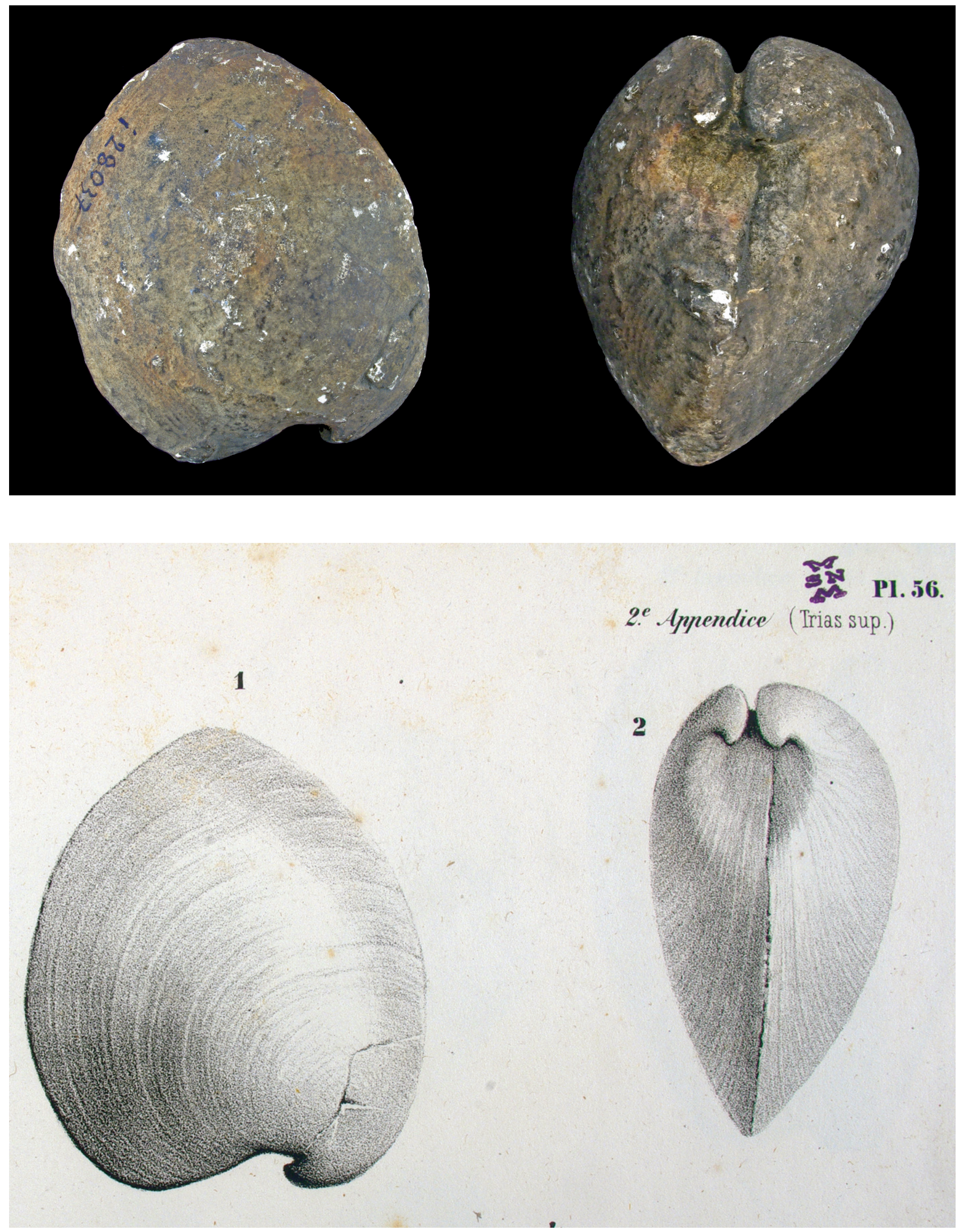

Fig.11 - MSNM i28042. Megalodon guembelii Stoppani, 1860-65. Plaster cast of a specimen from Songavazzo (Bergamo) illustrated by Stoppani, Tav. 56, figg. 1-2. x $1.26 \mathrm{ca}$. 